\title{
Desain dan Analisis Mata Pisau Pencacah Untuk Pengolahan Sampah Plastik Menggunakan Finite Element Analysis
}

\author{
Sigiet Haryo Pranoto ${ }^{1}$, Santi Yatnikasari ${ }^{2}$, Muhammad Noor Asnan ${ }^{3}$, Rizqi IImal Yaqin ${ }^{4}$ \\ 1,2,3 Program Studi Teknik Mesin, Fakultas Sains dan Teknologi, Universitas Muhammadiyah Kalimantan Timur \\ ${ }^{4}$ Program Studi Permesinan Kapal, Politeknik Kelautan dan Perikanan Dumai \\ ${ }^{1,2}$ Jl. Ir. H. Juanda No.15 Sidodadi, Kec. Samarinda Ulu, Kota Samarinda, Kalimantan Timur, 75124, Indonesia \\ ${ }^{4}$ Jl. Wan Amir No.1, Pangkalan Sesai, Dumai, 28826, Indonesia
}

E-mail: shp904@umkt.ac.id ${ }^{1}$, sy998@umkt.ac.id², mna985@umkt.ac.id², r.ilmalyaqin@politeknikkkpdumai.ac.id ${ }^{3}$

\section{Info Naskah:}

Naskah Masuk: 14 Juni 2020

Direvisi: 2 Agustus 2020

Diterima: 13 Agustus

\begin{abstract}
Abstrak
Sampah plastik adalah salah satu masalah lingkungan yang ada di Indonesia. Sampah plastik meupakan jenis sampah yang sulit terurai, sehingga perlu penanganan khusus untuk pengolahan masalah tersebut. Salah satu alternatif yang ditawarkan yaitu dengan pembuatan mesin pencacah plastik. Salah satu dalam manufaktur suatu mesin yaitu menrancang dan menganalisa komponen yang digunakanan. Mata pisau merupakan salah satu komponen penting pada mesin pencacah plastik. Simulasi model dari mata pisau sendiri perlu dilakukan untuk menganalisa kinerja dari mata pisau tersebut saat proses kinerja mesin tersebut. Permodelan simulasi dilakukan menggunakan software CAE. Bentuk meshing pada permodelan mata pisau yaitu menggunakan tetrahedral dan rasio meshing yaitu mendekati 1 . Hasil yang didapatkan dari proses permodelan mata pisau yaitu tegangan maksimum Von mises pada pembebanan $300 \mathrm{~N}, 500 \mathrm{~N}$ dan $700 \mathrm{~N}$ berturut turut sebesar $6,752 \times 10^{-3} \mathrm{MPa}, 2,845 \times 10^{-3} \mathrm{MPa}$ dan $1,575 \times 10^{-3} \mathrm{MPa}$. Sedangkan besaran displacement pada variasi pembebanan $300 \mathrm{~N}, 500 \mathrm{~N}$ dan $700 \mathrm{~N}$ berturut turut memiliki nilai $6,752 \times 10^{-2} \mathrm{~mm}, 1,125 \times 10^{-1} \mathrm{~mm}$ dan $1,575 \times 10^{-1} \mathrm{~mm}$. Safety factor pada simulasi ini dihasilakan yaitu memiliki nilai 15 yang artinya aman untuk semua variasi pembebanan karena memiliki nilai lebih dari 1.
\end{abstract}

\section{Keywords:}

von mises stress;

displacement;

safety factor;

finite element analysis;

blade.

\begin{abstract}
Plastic waste is one of the environmental problems in Indonesia. Plastic waste is a type of waste that is difficult to decompose, so it needs special handling for processing the problem. One alternative offered is by making a plastic chopper machine. One of the manufacturing of a machine is to design and analyze the components used. The blade is one of the important components of a plastic chopper. Model simulation of the blade itself needs to be done to analyze the performance of the blade during the performance of the machine. Simulation modeling is done using CAE software.. The form of meshing in the blade model is using tetrahedral and the meshing ratio is close to 1 . The results obtained from the blade modeling process are the maximum Von mises stress on the loading of $300 \mathrm{~N}, 500 \mathrm{~N}$, and $700 \mathrm{~N}$ respectively at $6.752 \times 10-3 \mathrm{MPa}, 2.845 \times 10-3 \mathrm{MPa}$ and $1,575 \mathrm{x}$ $10-3 \mathrm{MPa}$. While the amount of displacement in the variation of loading $300 \mathrm{~N}, 500 \mathrm{~N}$, and $700 \mathrm{~N}$ respectively has a value of $6.752 \times 10-2 \mathrm{~mm}, 1.125 \times 10-1 \mathrm{~mm}$ and $1.575 \times 10-1 \mathrm{~mm}$. The safety factor in this simulation is produced which has a value of 15 , which means it is safe for all loading variations because it has a value of more than 1 .
\end{abstract}




\section{Pendahuluan}

Perairan Indonesia merupakan salah satu perairan terbesar dan memiliki keanekaragaman sumber daya alam. Indonesia adalah negara maritim yang besar dengan luas lautan sekitar 5,9 juta $\mathrm{km}^{2}$ dan panjang pantai sekitar $81.000 \mathrm{~km}$ [1], sehingga Indonesia mempunyai kekayaan alam yang banyak, namun juga memiliki dampak tentang pencemaran lingkungan khususnya sampah plastik. Indonesia sendiri adalah negara penghasil pencemaran terhadap laut terbesar kedua [2]. Sampah plastik merupakan jenis sampah yang sulit untuk terurai, sehingga perlu penanganan khusus untuk pengolahan sampah plastik tersebut. Salah satunya dengan melakukan pencacahan dan didaur ulang [3]. Untuk itu perlu dilakukan pembuatan mesin pencacah plastik. Pengolahan sampah ini bertujuan untuk memberikan nilai tambah dan mengurangi pencemaran lingkungan [4]. Limbah sampah plastik juga dapat digunakan sebagai bahan tambah untuk menaikkan mutu campuran aspal [5].

Tahapan awal dalam proses pembuatan mesin pencacah plastik adalah desain atau rancangan mesin. Salah satu komponen terpenting dalam keberhasilan proses pencacahan adalah blade atau mata pisau. Sehingga diperlukan analisis pada mata pisau sebelum dilakukan proses manufaktur. Finite Element Analysis adalah salah satu metode yang banyak digunakan oleh peneliti untuk menganalisis tegangan dan menganalisis parameter lainnya [6]. Permodelan FEA menjadi alat yang dapat untuk mengoptimalkan dalam perancangan suatu mesin dan komponen mesin sebelum proses manufaktur [7]. FEA merupakan suatu metode analisis sebagai bantuan untuk mencari solusi dalam perhitungan secara teoritis [8]. Permodelan FEA mampu memprediksi dan menjadi solusi dari kekuatan suatu material yang dapat membantu engineer dalam melihat gaya pembebanan secara teoritis dari sebuah permodelan [9], [10].

Finite Element Analysis dapat menganalisis konsentrasi atau distribusi tegangan serta displacement pada suatu bentuk dan geometri tertentu [11]. Blade atau mata pisau dapat disimulasikan menggunakan Finite Element Analysis dengan berbagai macam software analisis. Regangan atau strain merupakan perbandingan perubahan panjang benda terhadap panjang mula-mula akibat suatu gaya dengan arah sejajar perubahan panjang tersebut [12]. Hasil regangan tersebut akan menghasilkan displacement pada material tersebut. Perhitungan regangan [13] dijabarkan pada persamaan (1).

$$
\varepsilon=\frac{\Delta l}{l_{0}}=\frac{l-l_{0}}{l_{0}}
$$

Dimana $\varepsilon$ adalah regangan, $\Delta l$ adalah perubahan panjang benda, $l_{0}$ adalah panjang awal benda dan $l$ adalah panjang benda setelah dikenai gaya/beban.

Penelitian sebelumnya mengenai analisis tegangan pada pisau mesin penghancur plastik menggunakan metode finite element analysis. Hasil dari penelitian tersebut menujukan pisau dapat digunakan untuk menghancurkan plastik jenis PET tanpa mengalami kegagalan bahan dari pisau tersebut [14]. Selain itu penelitian tentang perbedaan jenis bahan dan geometri pada pisau mesin pencacah plastik menggunakan Finite Element Method telah dilakukan. Hasilnya bahan dengan jenis AISI 1045 adalah jenis yang direkomendasikan karena memiliki tegangan von mises yang lebih rendah daripada lainnya [15]. Penelitian yang lain mempelajari tentang desain dari mesin penghancur plastik PET. Hasil simulasi dari model pisau dengan pembebanan $3000 \mathrm{~N}$ dimana desain pisau tidak akan gagal jika dibebani pembebanan PET sebesar 3000N [16]. Penggunaan permodelan untuk menganalisa optimasi pada pisau pemotong. Hasilnya dengan desain yang sudah di optimasi dapat memotong dua benda kerja dan memiliki analisa struktur yang baik [17]. Penelitian yang berbeda tentang mata pisau pada mesin pencacah dengan variasi getaran. Dimana adanya karakteritik perubahan deformasi pada model simulasi karena perbedaan karakteristik pembebanan yang dipengaruhi oleh karakteristik getaran [18].

Berdasarkan beberapa permasalahan yang sudah dirangkum dan dijelaskan sebelumnya, maka tujuan penelitian ini dilakukan untuk menganalisis tegangan dan kekuatan blade atau mata pisau mesin pencacah untuk pengolahan sampah plastik ketika dilakukan proses pencacahan plastik yang sebenarnya nantinya dengan menggunakan Finite Element Analysis (FEA). Hasil yang akan didapatkan meliputi von mises stress, displacement, dan safety factor sebagai acuan sebelum proses pembuatan mesin dilakukan. Dalam penelitian ini dilakukan dengan mengasumsikan simulasi statis menggunakan software CAE.

\section{Metode}

Permodelan gambar blade atau mata pisau digambar menggunakan sooftware CAD sebelum dilakukan analisis menggunakan software CAE. Sebelum pembuatan model mata pisau yang akan dianalisis, maka penentuan dimensi mata pisau seperti terlihat pada tabel 1. Bahan yang digunakan untuk pembuatan mata pisau dengan plat mild steel yang mempunyai sifat properti seperti Tabel 1 . Berdasarkan data parameter pada Tabel 2, maka data tersebut dimasukkan kedalam software simulasi untuk dilakukan analisis. Blade/mata pisau tersebut akan dioperasikan pada mesin pencacah dengan penggerak motor listrik 1 Phase dengan daya 2HP sehingga mata pisau tersebut akan beroperasi seperti yang dijabarkan Tabel 3 .

Tabel 1. Dimensi bentuk blade/mata pisau

\begin{tabular}{lc}
\hline \multicolumn{1}{c}{ Geometri } & Nilai \\
\hline Panjang & $128 \mathrm{~mm}$ \\
Lebar & $70 \mathrm{~mm}$ \\
Tebal & $8 \mathrm{~mm}$ \\
Sudut Kemiringan & $45^{\circ}$ \\
\hline
\end{tabular}

Tabel 2. Sifat mekanik blade/mata pisau [14]

\begin{tabular}{lc}
\hline \multicolumn{1}{c}{ Sifat } & Nilai \\
\hline Tensile strength & $640-840 \mathrm{MPa}$ \\
Yield Strength & $500-650 \mathrm{Mpa}$ \\
Hardness & $190-270 \mathrm{BHN}$ \\
Elongation & $8 \%$ \\
\hline
\end{tabular}


Tabel 3. Kondisi kerja blade/mata pisau

\begin{tabular}{lc}
\hline \multicolumn{1}{c}{ Parameter } & Nilai \\
\hline Kecepatan putar & $1440 \mathrm{rpm}$ \\
Daya & $2 \mathrm{HP}$ \\
Kapasitas cacahan & $50 \mathrm{~kg} / \mathrm{jam}$ \\
\hline
\end{tabular}

Sistem permodelan pada Finite Element Analysis juga sangat dipengaruhi oleh sistem meshing yang dilakukan pada objek yang akan dianalisis. Pada simulasi ini tipe meshing yang digunakan adalah tipe tetrahedral dengan jumlah node sebesar 2565 dan element sebesar 1307. Hal ini bertujuan untuk menyamakan rasio elemen yang satu dengan yang lainnya agar lebih kecil karena hasil analisis yang baik dan lebih teliti dipengaruhi juga oleh bentuk mesh yang baik. Rasio mesh yang baik adalah perbandingan rasio setiap elemennya adalah 1 atau mendekati 1 . Pengaturan bentuk mesh pada blade atau mata pisau dapat dilihat seperti Gambar 1.

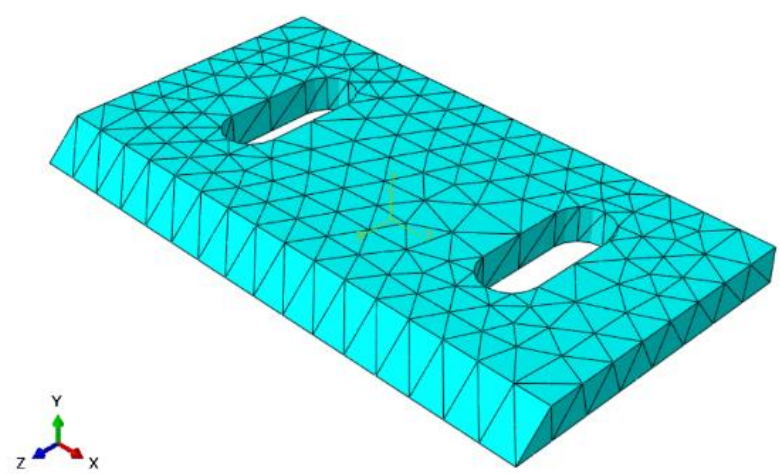

Gambar 1. Meshing Dengan Tipe Tetrahedral

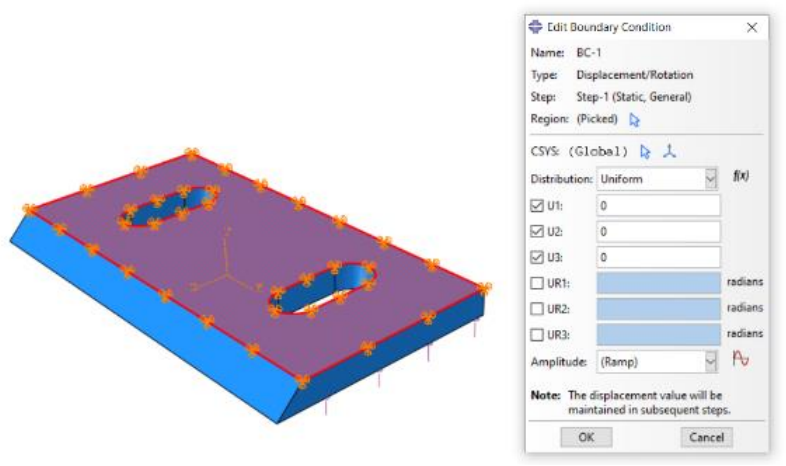

Gambar 2. Peletakan Initial Condition
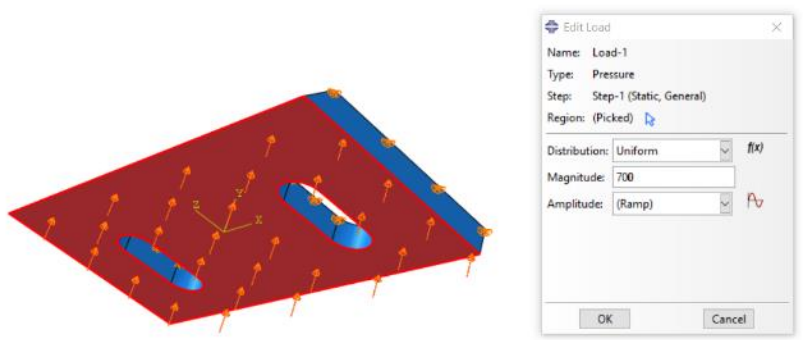

Gambar 3. Peletakan Pembebanan Pada Pisau Pencacah
Selanjutnya adalah Initial condition yang digunakan adalah tipe displacement/rotation dengan nilai 0 pada setiap sumbu X,Y, dan Z sehingga komponen ini hanya diam atau tertahan jika dikenai pembebanan. Hal ini dimaksudkan karena pada daerah ini nantinya akan dikunci dengan baut sehingga tidak ada pergerakan sedikitpun. Untuk mengetahui peletakan initial condition dapat dilihat pada Gambar 2. Pembebanan yang diberikan pada simulasi ini adalah tipe pressure. Pada bagian ini yang nantinya akan mendapatkan pembenanan dari sampah yang akan dicacah sehingga bersinggungan langsung dengan material sampah tersebut. Peletakan daerah pembebanan dapat dilihat seperti Gambar 3 .

Hasil solusi simulasi menggunakan software CAE untuk menganalisa tegangan dan displacement. Analisis secara statis digunakanan untuk mengetahui nilai dari finite element analysis dari persamaan tegangan von mises yaitu Perhitungan tegangan von mises pada elemen-elemen Finite Element Analysis [19] dijabarkan pada persamaan (2).

$$
\left\{\begin{array}{l}
\sigma_{x x} \\
\sigma_{y y} \\
\sigma_{z z}
\end{array}\right\}=\frac{E}{(1+v)(1-2 v)}\left\{\begin{array}{c}
(1-v) \varepsilon_{x}+v \varepsilon_{y}+v \varepsilon_{z} \\
v \varepsilon_{x}+(1-v) \varepsilon_{y}+v \varepsilon_{z} \\
v \varepsilon_{x}+\varepsilon_{y}+(1-v) \varepsilon_{z}
\end{array}\right\}
$$

dimana E adalah Modulus Elastisitas bahan, $l$ adalah panjang dari geometri bahan yang dimodelkan [19].

Setelah tahap simulasi dari simulasi permodelan tersebut akan mendapatkan nilai dari Von mises stress, displacement dan safety factor tiap variasi gaya yang diberikan. Nilai tersebut akan dianalisa nilai maksimal yang disajikan sebagai acuan desain dari model.

\section{Hasil dan Pembahasan}

\subsection{Von Mises Stress}

Proses analisis dilakukan dengan perbedaan 3 variasi pembebanan yaitu $300 \mathrm{~N}, 500 \mathrm{~N}$, dan $700 \mathrm{~N}$ yang menunjukkan pembebanan kemampuan blade dapat bekerja dalam proses mencacah plastik. Hal ini dimaksudkan untuk mengetahui perbedaan distribusi tegangan von mises pada mata pisau pada kondisi operasional kerja mesin. Hasil analisis terlihat pada Gambar 4, Gambar 5, dan Gambar 6.

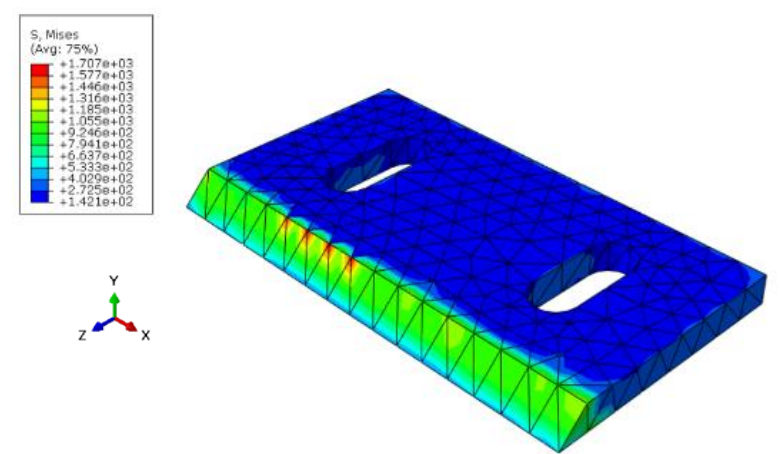

Gambar 4. Von Mises Stress $300 \mathrm{~N}$ 


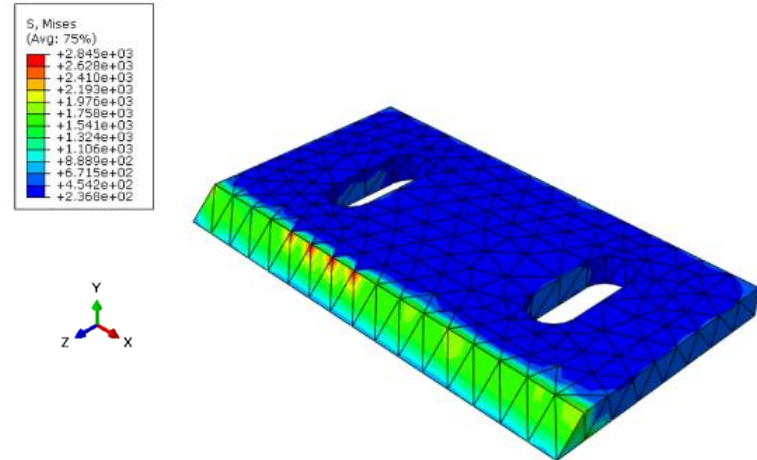

Gambar 5.Von Mises Stress pada $500 \mathrm{~N}$
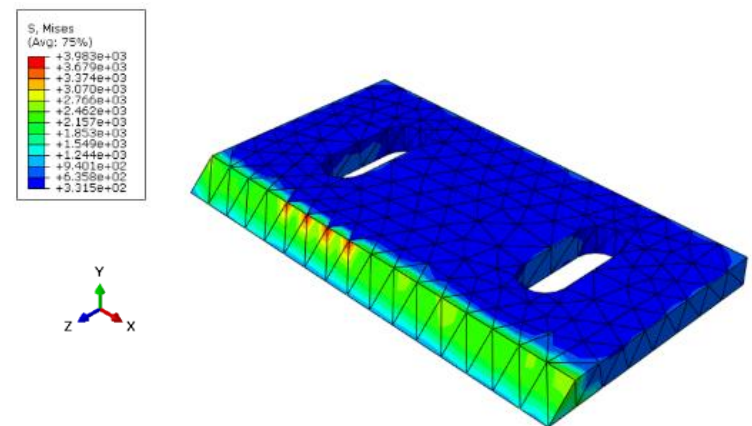

Gambar 6. Von Mises Stress pada $700 \mathrm{~N}$

Hasil analisis yang dilakukan bahwa distribusi tegangan yang terjadi dengan load yang diberikan sebesar $300 \mathrm{~N}$ didapatkan tegangan maksimum atau von mises stress sebesar $1.707 \times 10^{3} \mathrm{~N} / \mathrm{m}^{2}$ atau setara dengan $1.707 \times$ $10^{-3} \mathrm{MPa}$. Selain itu rata-rata tegangan berada di area warna hijau yang berkisar sekitar $9.246 \times 10^{2} \mathrm{~N} / \mathrm{m}^{2}$ atau setara dengan $9.246 \times 10^{-2} \mathrm{MPa}$.

Pada load yang diberikan sebesar $500 \mathrm{~N}$ terdapat peningkatan von mises stress dengan nilai maksimum sebesar $2.845 \times 10^{3} \mathrm{~N} / \mathrm{m}^{2}$ atau setara dengan $2.845 \times 10^{-3}$ $\mathrm{MPa}$. Rata-rata distribusi tegangan juga masih di area warna hijau sekitar $1.541 \times 10^{3} \mathrm{~N} / \mathrm{m}^{2}$ atau setara dengan $1.541 \times 10^{-3} \mathrm{MPa}$. Percobaan terakhir dengan load sebesar $700 \mathrm{~N}$ didapatkan hasil tegangan maksimum sebesar 3.983 $\times 10^{3} \mathrm{~N} / \mathrm{m}^{2}$ atau setara dengan $3.989 \times 10^{-3} \mathrm{MPa}$

\subsection{Displacement}

Displacement merupakan besar perubahan bentuk atau geometri dari suatu benda akibat dari gaya yang diterimanya. Hasil analisis terhadap besaran displacement yang terjadi seperti pada Gambar 7, Gambar 8, dan Gambar 9. Hasil analisis simulasi didapatkan data bahwa pada tegangan $300 \mathrm{~N}$ didapatkan displacement sebesar $6.752 \times$ $10^{-5} \mathrm{~m}$ atau setara dengan $6.752 \times 10^{-2} \mathrm{~mm}$. displacement yang terjadi sangat kecil yaitu $<1 \mathrm{~mm}$. Pada tegangan 500 $\mathrm{N}$ dipatkan nilai displacement sebesar $1.125 \times 10^{-4} \mathrm{~m}$ atau setara dengan $1.125 \times 10^{-1} \mathrm{~mm}$. Hasil analisis pada tegangan $700 \mathrm{~N}$ didapatkan hasil $1.575 \times 10^{-4} \mathrm{~m}$ atau setara dengan $1.575 \times 10^{-1} \mathrm{~mm}$. Dari ketiga tegangan yang diterima oleh mata pisau, displacement yang terjadi sangatlah kecil dan hanya terletak diujung sisi tajam mata pisau untuk memotong.

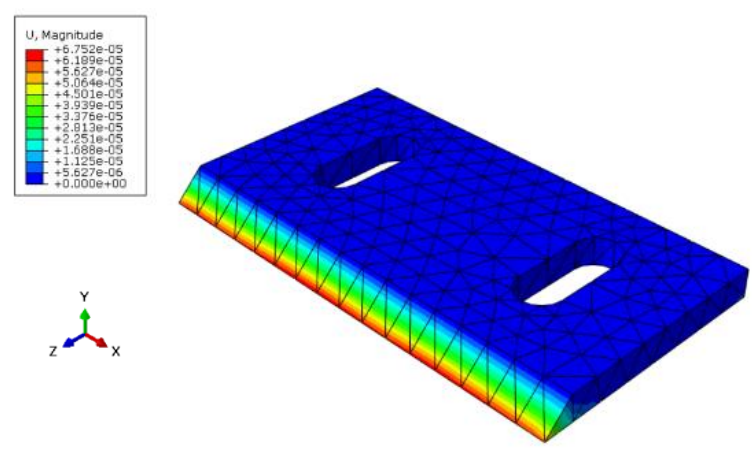

Gambar 7. Displacement Pada Pembebanan 300 N

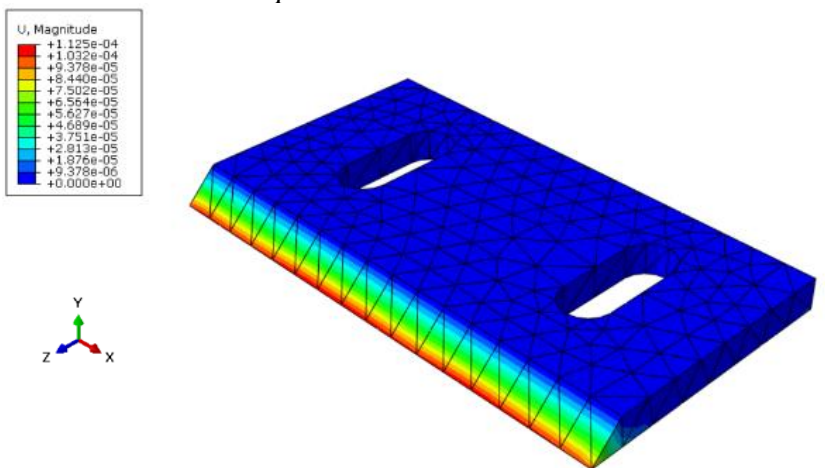

Gambar 8. Displacement Pada Pembebanan 500 N

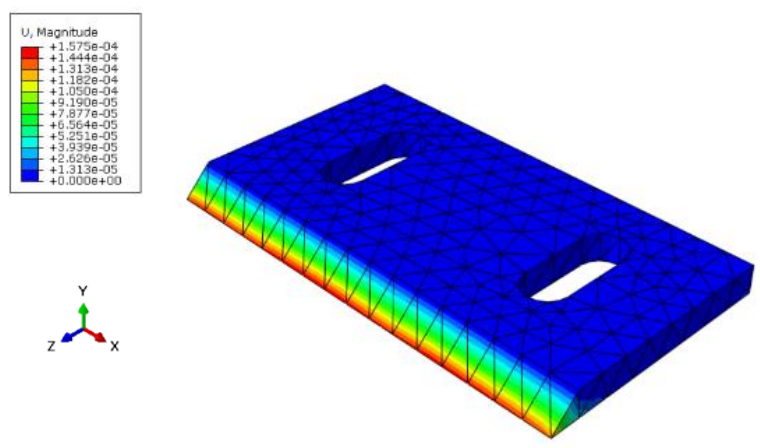

Gambar 9. Displacement Pada Pembebanan 700 N

Hasil analisis ini menunjukkan bahwa dengan tegangan yang diberikan mata pisau sangat aman dan dikarenakan displacement yang kecil maka dapat diabaikan sehingga tidak terdapat perubahan geometri pada mata pisau ini. Hal tersebut dikarenakan displacement yang terjadi masih pada daerah elastis sehingga pengaruh perubahan bentuk pada model pahat sangat kecil [17], [20]. Displacement menjadi hal yang penting dalam kasus ini, jika terdapat perubahan displacement maka geometri akan berubah dan fungsi komponen tersebut tidak dapat optimal.

Dari hasil simulasi, ketika komponen diberi pembebanan yang tinggi tetapi tidak menimbulkan displacement yang besar, bahkan displacement relatif kecil karena jika komponen yang diberi pembebanan tidak dapat menahan beban tersebut maka komponen tersebut akan rusak [11]. 


\subsection{Safety Factor}

Safety factor merupakan tingkat keamanan yang dimiliki oleh suatu benda. Safety factor adalah salah satu parameter penting dalam melakukan desain dan pengujian tegangan pada suatu bentuk model apakah objek tersebut aman atau tidak [21]. Nilai safety factor yang baik adalah jika nilai minimum yang didapatkan lebih besar dari 1 [22]. Nilai safety factor dari hasil simulasi pada blade/mata pisau seperti terlihat pada Gambar 10.

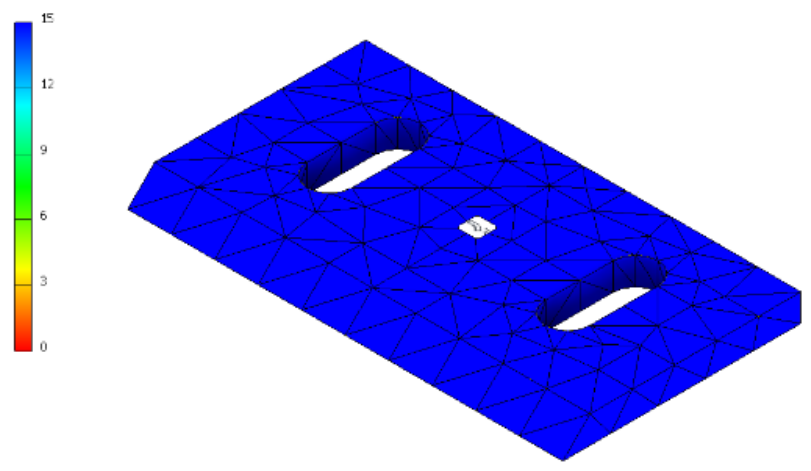

Gambar 10. Safety Factor Pada Blade/Mata Pisau

Berdasarkan hasil simulasi didapatkan nilai safety factor sebesar 15. Daerah hasil simulasi model didapatkan keseluruhan berwarna biru. Nilai safety factor dari model diperoleh dari pembagian pembebanan maksimum bahan pada model dengan nilai pembebanan maksimum yang terjadi atau dapat ditunjukkan persamaan (3) [23].

$$
S F=\frac{\sigma_{\max }}{\sigma_{\max \text { bahan }}}
$$

Simulasi model pada pembebanan $700 \mathrm{~N}$ menghasilkan nilai safety factor lebih dari 15 pada teoritisnya. Namun, pembacaan pada software merupakan pembacaan angka maksimum yaitu 15 yang merupakan angka paling aman pada desain model simulasi. Hasil safety factor tersebut menunjukkan keamaan bahwa model blade/mata pisau aman dari tegangan yang diberikan. Nilai safety factor yang didapatkan > 1 sehingga mata pisau ini aman untuk digunakan.

\section{Kesimpulan}

Hasil analisis yang telah dilaksanakan dapat ditarik kesimpulan bahwa: Distribusi tegangan pada permodelan blade atau mata pisau yang telah didesain/dirancang dengan pembebanan sebesar $300 \mathrm{~N}, 500 \mathrm{~N}$, dan $700 \mathrm{~N}$ mengalami peningkatan disetiap pembenanan. Dari hasil analisis didapatkan distribusi tegangan tertinggi sebesar $3.989 \times 10^{-}$ $3 \mathrm{MPa}$ dan hanya sedikit daerah yang mengalami konsentrasi dengan tegangan tinggi. Displacement yang terjadi pada permodelan blade/mata pisau juga sangat kecil. Hal ini dapat dibuktikan dengan displacement tertinggi sebesar $1.575 \times 10^{-1} \mathrm{~mm}$ pada pembebanan $700 \mathrm{~N}$. Nilai ini sangat kecil mendekati 0 sehingga dapat diabaikan dan tidak ada terjadi perubahan geometri pada blade/mata pisau. Nilai safety factor yang didapatkan cukup besar yaitt sekitar 15. Hal ini tergolong cukup aman karena nilai safety factor yang aman adalah minimum 1 .
Untuk penelitian selanjutnya, simulasi dan analisis dari salah satu komponen mesin pencacah untuk bisa terus dilanjutkan kepada komponen mesin yang lain karena dengan adanya simulasi dan analisis sangat membantu peneliti sebelum melakukan proses manufaktur.

\section{Daftar Pustaka}

[1] R. Lasabuda, "Pembangunan Wilayah Pesisir Dan Lautan Dalam Perspektif Negara Kepulauan Republik Indonesia," $J$. Ilm. Platax, vol. I, no. 2, pp. 92-101, 2013.

[2] J. R. Jambeck et al., "Plastic waste inputs from land into the ocean," 2015. doi: 10.1017/CBO9781107415386.010.

[3] N. D. Anggraeni and A. E. Latief, "Rancang Bangun Mesin Pencacah Plastik Tipe Gunting," J. Rekayasa Hijau, vol. 2, no. 2, pp. 185-190, 2018.

[4] M. Yamin, D. Satyadarma, and P. Naipospos, "Perancangan mesin pencacah sampah type crusher," in Proceeding seminar ilmiah nasional komputer dan sistem intelijen, 2008, pp. 20-21.

[5] T. W. Suroso, "Pengaruh Penambahan Plastik Ldpe (Low Density Poly Ethilen) Cara Basah Dan Cara Kering Terhadap kinerja Campuran Beraspal," Media Komun. Tek. Sipil, no. 3, pp. 208-222, 2008.

[6] H. J. Lin, W. M. Lai, and Y. M. Kuo, "Effects of stacking sequence on nonlinear hydroelastic behavior of composite propeller blade," J. Mech., vol. 26, no. 3, pp. 293-298, 2010, doi: 10.1017/S1727719100003841.

[7] S. H. Pranoto and M. Mahardika, "Design and finite element analysis of micro punch CNC machine modeling for medical devices," AIP Conf. Proc., vol. 1941, 2018, doi: $10.1063 / 1.5028079$.

[8] T. Fadiji, C. J. Coetzee, T. M. Berry, A. Ambaw, and U. L. Opara, "The efficacy of finite element analysis (FEA) as a design tool for food packaging: A review," Biosyst. Eng., vol. 174, pp. 20-40, 2018, doi: 10.1016/j.biosystemseng.2018.06.015.

[9] R. I. Yaqin, A. B. Prasetiyo, P. Pritiansyah, M. H. Amrullah, and B. M. T. Pakpahan, "Studi Numerik Umur Kelelahan (Fatigue Life) Pada Propeller Kapal Penangkap Ikan Dengan Kapasitas Mesin 24 Hp," JTT (Jurnal Teknol. Ter., vol. 6, no. 1, pp. 8-17, 2020, doi: 10.31884/jtt.v6i1.245.

[10] R. I. Yaqin, J. P. Siahaan, and S. H. Pranoto, "Analisis Tegangan Propeller Kapal Penangkap Ikan Di Kota Dumai Menggunakan Finite Element Analysis," JTT (Jurnal Teknol. Ter., vol. 5, no. 2, p. 56, 2019, doi: 10.31884/jtt.v5i2.225.

[11] J. Pratama and M. Mahardika, "Finite element analysis to determine the stress distribution, displacement and safety factor on a microplate for the fractured jaw case," AIP Conf. Proc., vol. 1941, pp. 1-7, 2018, doi: 10.1063/1.5028080.

[12] N. B. Dantulwar, R. G. Maske, and J. T. Patel, "Finite Element Analysis of Ball Valve Assembly for Earthquakes," in International Conference on Ideas, Impact and Innovation in Mechanical Engineering, 2017, no. 6, pp. $1460-1467$.

[13] P. Frauenfelder and P. Huber, Introduction to Physics. 1977.

[14] M. F. Nasr and K. A. Yehia, "Stress Analysis of a Shredder Blade for Cutting Waste Plastics," J. Int. Soc. Sci. Eng., vol. 1, no. 1, pp. 9-12, 2019, doi: 10.21608/jisse.2019.20292.1017.

[15] C. P. Yepes, R. M. A. Pelegrina, and M. G. J. Pertuz, "Analysis by means of the finite element method of the blades of a PET shredder machine with variation of material and geometry," Contemp. Eng. Sci., vol. 11, no. 83, pp. 4113-4120, 2018, doi: 10.12988/ces.2018.88370.

[16] A. E. Ikpe and O. Ikechukwu, "Design of Used PET Bottles 
Crushing Machine for Small Scale Industrial Applications," Int. J. Eng. Technol. IJET, vol. 3, no. 3, pp. 157-168, 2017, doi: 10.19072/ijet.327166.

[17] Z. Yin and L. Xu, "Finite element analysis and optimization design of paper cutter cutting blade based on ANSYS," in Proceedings International Conference on Robots and Intelligent System, 2018, pp. 475-478, doi: 10.1109/ICRIS.2018.00125.

[18] X. Shen, S. Qian, and Z. Yu, "The Research of Crusher Blade Carrier Shaft Based on Balancing Test and Dynamic Analysis," Appl. Mech. Mechatronics Intell. Syst., pp. 7984, 2016, doi: 10.1142/9789814733878_0013.

[19] S. O. Dapas, "Analisis Struktur Rangka Batang," J. Ilm. Media Eng., vol. 1, no. 2, pp. 156-160, 2011.

[20] Z. Abidin and B. R. Rama, "Analisa Distribusi Tegangan Dan Defleksi Connecting Rod Sepeda Motor $100 \mathrm{Cc}$ Menggunakan Metode Elemen Hingga," J. Rekayasa Mesin
Univ. Sriwij., vol. 15, no. 1, pp. 30-39, 2015.

[21] B. Setyono, Mrihrenaningtyas, and A. Hamid, "Perancangan Dan Analisis Kekuatan Frame Sepeda Hibrid 'Trisona' Menggunakan Software Autodesk Inventor," J. IPTEK, vol. 20, no. 2, p. 37, 2016, doi: 10.31284/j.iptek.2016.v20i2.43.

[22] T. C. K. Reddy and K. N. Rao, "Design and Simulation of A Marine Propeller," Int. J. Res. Adv. Eng. Technol., vol. 5, no. 1, pp. 111-128, 2015.

[23] M. Y. Z. Aji, I. P. Mulyatno, and H. Yudho, "Analisa Kekuatan Modifikasi Main Deck Akibat Penggantian Mooring Winch Pada Kapal Accomodation Work Barge 5640 Dwt Dengan Metode Elemen Hingga," J. Tek. Perkapalan, vol. 4, no. 1, pp. 74-82, 2016. 